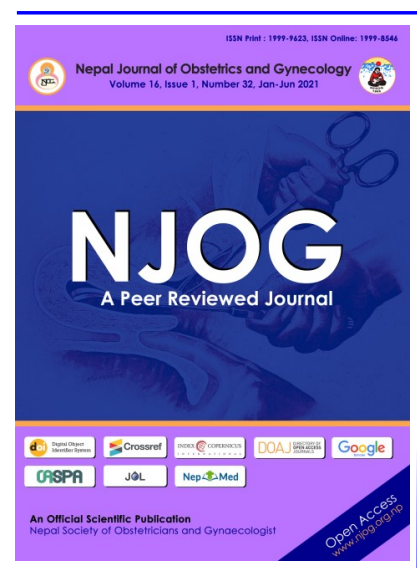

CORRESPONDENCE

Dr Chandana Chandregowda

Department of OBG, Vydehi Institute of medical sciences, Bengaluru, India

Email:

chandanachandregowda @gmail.com;

Phone: +91 8095993048

Received: January 19, 2021 Accepted: May 1, 2021

\section{Citation:}

Chandregowda C, Reddy SA, Datti S, Venkatesh S. Diagnosis of abnormal uter ine bleeding using PALM COEIN classification and its management: An institutional experience. Nep J Obstet Gynecol. 2021;16 (32):38-42. DOI: https:// doi.org/10.3126/ njog.v16i1.37515

\title{
Diagnosis of abnormal uterine bleeding using PALM COEIN classification and its management: An institutional experience
}

\author{
Chandana chandregowda, Swathi Aswath Reddy, Sujatha Datti, \\ Shreedhar Venkatesh \\ Department of OBGYN, Vydehi Institute of medical sciences, Bengaluru
}

\section{ABSTRACT}

Aims: Categorization and treatment of abnormal uterine bleeding based on FIGO - PALM COEIN classification system

Methods: A prospective cross-sectional observational study was conducted in the Department of Obstetrics and Gynaecology, Vydehi Institute of Medical Sciences and Research Centre, Bengaluru for a period of 1year from January 2019 to December 2019. All cases with abnormal uterine bleeding in 20 - 50 years of age were taken. Clinical details and imaging tests recorded, and categorized by FIGO- PALM COEIN classification for diagnosis and treatment. Statistical Package for Social Sciences version 21 was used to analyse the data and presented as frequencies and percentages.

Results: Out of 300 women of AUB, 190 had structural (PALM) and 110 women had nonstructural (COEIN) aetiology; 138 women among 300 underwent hysterectomy and 20 patients underwent hysteroscopic polypectomy. Levonorgestrel intrauterine device inserted in 40 patients, 85 women were managed medically and 17 women lost to follow-up for further management.

Conclusion: FIGO PALM-COEIN classification system for the diagnosis and treatment of abnormal uterine bleeding was adopted for the uniform standard.

Keywords: Abnormal uterine bleeding, leiomyoma, ovulatory disorder, PALMCOEIN

\section{INTRODUCTION}

Abnormal uterine bleeding (AUB) is the most common problem encountered among the non-pregnant women in the reproductive age group. It has substantial effect on health-related quality of women's life. AUB is caused by a variety of pelvic pathology, systemic diseases or by medication related. The investigation and management of AUB will not be uniform and systematic unless a standardised method is in practice.

PALM COEIN classification system (Polyp, Adenomyosis, Leiomyoma, Malignancy and hyperplasia) for structural causes and (Coagulopathy, Ovulatory disorders, Endometrial, Iatrogenic and Not otherwise classified) for nonstructural causes of AUB was proposed by International Federation of
Gynecology and Obstetrics (FIGO) in 2011. ${ }^{1}$ In the 2018 FIGO system, AUB secondary to anticoagulants was moved from the coagulopathy category to the iatrogenic. AUB not otherwise classified contains rare etiologies and include arteriovenous malformations (AVMs), myometrial hyperplasia, and endometritis. ${ }^{2}$ Across the globe many gynaecological societies have adopted PALM COEIN system to revise new guidelines for diagnosis and management of AUB. There are very limited data available in Indian women with Abnormal Uterine Bleeding (AUB) using FIGO - PALM COEIN classification system for overall treatment, hence our study was conducted.

The study was done to categorize women with AUB according to 
FIGO - PALM COEIN etiological classification system for the purpose of respective management options.

\section{METHODS}

A prospective cross-sectional observational study was conducted in the Department of Obstetrics and Gynaecology, Vydehi Institute of Medical Sciences and Research Centre, Bengaluru for a period of 1 year from January to December 2019. Institutional ethical committee clearance was taken. A total of 300 non-pregnant women of reproductive age between 20- 50 years with abnormal uterine bleeding were included in the study. The women with obvious local lesions on vagina and vulva were excluded from the study. The written informed consent was taken from patients participated in the study.

All the women in the study were clinically evaluated. A pelvic ultrasound was done to assess structural causes followed by hysteroscopy or saline sonography for abnormal uterine cavity and MRI to rule out myometrial pathology. Office endometrial biopsy or hysteroscopy guided biopsy was taken in women above $40 \mathrm{yrs}$ and for the patients with risk factors for endometrial cancer. For the evaluation of non-structural causes bleeding time, clotting time, and thyroid function test were done for all cases; and prothrombin time and activated partial thromboplastin time wherever required.

Coagulopathy was labeled for all known cases of coagulation disorder. Ovulatory disorder was defined as untimely and variable amount of bleeding. Endometrial disorders were the cause of AUB when timely or cyclical pattern of bleeding was observed. If symptoms were seen following the use of hormonal steroids or contraceptive device in the preceding 3 months then the cause of AUB was labeled as iatrogenic. The rest were included in the not yet classified category. The causes of AUB were categorized according to PALM-COEIN classification system and specific treatment was provided.

Data were tabulated in Microsoft Excel and SPSS version 21.0 software (SPSS Inc., Chicago, IL, USA) was used for statistical analysis. The descriptive statistics were presented as frequencies and percentages.

\section{RESULTS}

Out of 300 cases with AUB, 177 (59\%) were seen in the age group of 41-50yrs followed by 31- $40 \mathrm{yrs}$ $(\mathrm{n}=99,33 \%)$ and $20-30 \mathrm{yrs}(\mathrm{n}=24,8 \%)$. Among 300 women $73 \%$ were parous women. Majority $(66 \%)$ of the patients suffered symptoms of abnormal uterine bleeding for a period of more than 6 months. The most common pattern found was heavy menstrual bleeding followed by metrorrhagia, polymenorrhoea, menometrorrhagia, and hypomenorrhoea. [Table-1]

Table-1: Abnormal bleeding pattern

\begin{tabular}{lcc}
\hline Bleeding pattern & $\mathrm{N}$ & $\%$ \\
\hline Heavy menstrual bleeding & 170 & 56.6 \\
Metrorrhagia & 60 & 20 \\
Polymenorrhoea & 35 & 11.6 \\
Menometrorrhagia & 30 & 10 \\
Hypomenorrhoea & 5 & 1.6 \\
\hline
\end{tabular}

More than $60 \%$ had structural causes of AUB predominantly with leiomyoma and Adenomyosis. Ovulatory disorder was the commonest finding in non-structural causes. In the polyp group out of 25 women (8.3\%), 10 women had cervical polyp and 15 women had endometrial polyp. Around 68 (22.6\%) women had adenomyosis diagnosed on ultrasound and among them 10 patients had fibroid as well. Among 95 women with fibroid uterus majority had intramural fibroid and 18 women had submucosal fibroid. In 194 women endometrial biopsy was done. In 18 women histopathology showed endometrial hyperplasia and 2 women had endometrial carcinoma. In COEIN group 3 women were diagnosed with coagulopathy they were diagnosed to have idiopathic thrombocytopenic purpura with low platelet counts. Ovulatory disorders were found in 65 women and majority of women in ovulatory group demonstrated proliferative endometrium in histopathology. In iatrogenic group among 18 women, 5 were using intrauterine contraceptive device and 11 women were taking hormones irregularly in the preceding 3 months (COCs, emergency contraceptive pills) and 2 women were on anticoagulation for medical condition. [Table-2]

Table-2: Distribution of causes of AUB according to PALM-COEIN classification

\begin{tabular}{ll}
\hline PALM category & $\mathrm{N}(\%)$ \\
\hline AUB-P (Polyp) & $2(8.3 \%)$ \\
AUB-A (Adenomyosis) & $68(22.3 \%)$ \\
AUB-L (Leiomyoma) & $95(31.6 \%)$ \\
AUB-M (Malignancy & $20(6.6 \%)$ \\
and hperplasia) & \\
\hline Total & $190(63.3 \%)$ \\
\hline
\end{tabular}




\begin{tabular}{ll}
\hline COEIN category & $\mathrm{N}(\%)$ \\
\hline AUB-C (Coagulopathy) & $3(1 \%)$ \\
AUB-O (Ovulatory disorders) & $65(21.6 \%)$ \\
AUB-I (Iatrogenic) & $18(6 \%)$ \\
AUB-E (Endometrial) & $6(2 \%)$ \\
AUB-N (not yet classified) & 0 \\
\hline Total & $110(36.6 \%)$ \\
\hline
\end{tabular}

$64.7 \%$ (194/300) had endometrial biopsy and majority had physiological endometrial pattern (either secretory or proliferative). Only two had endometrial carcinoma. [Table-3]

Table-3: Histopathological pattern of endometrial biopsy $(\mathrm{N}=194)$

\begin{tabular}{lcc}
\hline Histopathological pattern & $\mathrm{N}$ & $\%$ \\
\hline Secretory & 114 & 58.4 \\
Proliferative & 56 & 28.8 \\
Simple hyperplasia & 10 & 3.3 \\
Complex hyperplasia & 8 & 2.6 \\
Disordered endometrium & 4 & 1.3 \\
Malignancy & 2 & 1 \\
\hline
\end{tabular}

Treatment was individualised based on presentation, need of fertility and contraception. Majority (138, $46 \%$ ) underwent hysterectomy and 20 had hysteroscopic polypectomy. Levonorgestrel intrauterine device inserted in 40 women, 85 women were managed medically and 17 women lost to follow-up for further management. [Table-4]

\section{DISCUSSION}

In the present study, most of the women were in the perimenopausal age group (41-50 years). The age distribution of AUB in our study revealed that $59 \%$ of cases belonged to $41-50$ years and menorrhagia $(56.6 \%)$ was the commonest presenting complaint. About $66 \%$ of women had symptoms for more than 6 months. These findings were similar to a study by Jaitly et $\mathrm{al}^{3}$ and Shoba PS et $\mathrm{al}^{4}{ }^{4}$ This may be due to anovulation and increased resistance to gonadotrophic stimulation.

In our study the structural PALM component (63.3\%) contributed more for the cause of AUB as compared to functional COEIN (36.6\%) which is similar to study done by Betha $\mathrm{K}$ et al ${ }^{5}$ whereas in study done by Devanshi Mishra et $\mathrm{al}^{6}$, both the components of PALM COEIN classification was equally contributing to the clinical causes of AUB. Leiomyoma, AUB-L (31.6\%) being the major cause of AUB in our present study similar to other studies which also showed leiomyoma as the predominant cause of AUB. Leiomyomas are the major contributor in structural cause for AUB. Heavy menstrual bleeding (HMB) was the commonest presenting complaint with leiomyoma. The symptoms of AUB are more related to the location and

Table-4: Treatment approach for women with AUB

\begin{tabular}{|c|c|c|c|}
\hline Diagnosis & $\mathrm{N}$ & Investigation & Treatment \\
\hline Polyp & 25 & $\begin{array}{l}\text { TVS, Hysteroscopy, } \\
\text { Sono-hysterogram }\end{array}$ & $\begin{array}{l}\text { Cervical polypectomy/Hysterscopic endometrial polyp resec- } \\
\text { tion in } 25 \text {, } \\
\text { LNG -IUS insertion done in } 4 \text { cases after polypectomy }\end{array}$ \\
\hline Adenomyosis & 68 & TVS, MRI pelvis & $\begin{array}{l}\text { Hysterectomy done in } 46 \text { cases } \\
\text { Medical management in } 5 \text { cases } \\
\text { LNG -IUS insertion done in } 11 \text { cases } \\
\text { Adenomyomectomy in } 3 \text { cases } \\
\text { Lost to follow up in } 3 \text { cases }\end{array}$ \\
\hline Leiomyoma & 95 & $\begin{array}{l}\text { TVS, Sono- } \\
\text { hysterogram }\end{array}$ & $\begin{array}{l}\text { Medical management in } 23 \text { cases } \\
\text { Myomectomy by laproscopic/hysteroscopic in } 13 \text { cases } \\
\text { LNG -IUS insertion done in } 6 \text { cases } \\
\text { Hysterectomy done in } 45 \\
\text { Lost to follow up } 8 \text { cases }\end{array}$ \\
\hline $\begin{array}{l}\text { Malignancy } \\
\text { and hyperplasia }\end{array}$ & 20 & Endometrial biopsy & $\begin{array}{l}\text { Hysterectomy in } 15 \text { cases } \\
\text { Medical management } 3 \text { cases LNG -IUS insertion in } 1 \text { case } \\
\text { Lost to follow up } 2 \text { case }\end{array}$ \\
\hline Coagulopathy & 3 & $\begin{array}{l}\text { Platelet count, coagu- } \\
\text { lation profile }\end{array}$ & Medical management in 3 cases \\
\hline $\begin{array}{l}\text { Ovulatory dis- } \\
\text { orders }\end{array}$ & 65 & Endometrial biopsy & $\begin{array}{l}\text { Hysterectomy } 32 \text { cases } \\
\text { Medical management } 15 \text { cases } \\
\text { LNG -IUS insertion done in } 18 \text { cases }\end{array}$ \\
\hline Iatrogenic & 18 & $\begin{array}{l}\text { History of hormonal } \\
\text { intake/copper T inser- } \\
\text { tion }\end{array}$ & $\begin{array}{l}\text { Medical management in } 13 \text { cases } \\
\text { Lost to follow up } 5 \text { case }\end{array}$ \\
\hline Endometrial & 6 & Endometrial biopsy & Antibiotic course and Medical treatment in 6 cases \\
\hline
\end{tabular}


size of the myoma. Submucous fibroids have high association with AUB, as increased endometrial surface area contributes to excessive bleeding.

Polyps (AUB-P) were found in $25(8.3 \%)$ women in the present study. Similar finding $(11.2 \%)$ was seen in a study done by Doraiswamy et al. ${ }^{7}$ Women with endometrial polyps presented to us as intermenstrual bleeding, HMB and postmenopausal bleeding; and the diagnosis was made on the basis of increased endometrial thickening with a feeder blood vessel on a transvaginal pelvic ultrasound that was confirmed by visualization with sonohysterography or hysteroscopy. In our study 10 Cervical polyps were diagnosed on clinical examination, 15 women had endometrial polyps diagnosed either on ultrasound or hysteroscopy.

The cause of AUB due to adenomyosis AUB-A was seen in about $68(22.6 \%)$ women in our study, similar to the studies done by Qureshi et al, ${ }^{8}$ Taran et al ${ }^{9}$ and Templeman et al. ${ }^{10}$ It is one of the common causes of AUB between 35-50years. Adenomyosis is the presence of ectopic endometrial tissue in the myometrium. The diagnosis of adenomyosis by ultrasound examination is sometimes practically difficult, MRI is the better one and diagnostic is the histopathology only. In a study by Taran et $\mathrm{al}^{9}, 70$ to $80 \%$ of women undergoing hysterectomy for adenomyosis are in their fourth and fifth decade of life and are multiparous. Multiparous women had high incidence of adenomyosis. It was explained that during pregnancy adenomyotic foci to be included in the myometrium due to the invasive nature of the trophoblast leading development of Adenomyosis. ${ }^{10,11}$

In the present study, AUB- M (Malignancy and hyperplasia) endometrial hyperplasia accounted for $9.2 \%$ and adenocarcinoma for $1 \%$ which was similar to the study done by Mishra et $\mathrm{al}^{6}$ and Singh et al. ${ }^{12}$ Both simple hyperplasia and complex hyperplasia with or without atypia are known to be precancerous lesion of endometrial carcinoma and are reported to be $1 \%-3 \%$ in hyperplasia without atypia and $8 \%-29 \%$ in hyperplasia with atypia. ${ }^{13}$

Ovulatory disorders AUB-O seen in 65 patients (21.6\%) being more important cause amongst functional causes in the present study which was similar to findings of Singh et $\mathrm{al}^{12}$ and Mishra. ${ }^{6}$ Coagulopathy (AUB-C) is found in $1 \%$ of women presenting with AUB, in the present study which is similar to Qureshi et al study $(0.3 \%)^{8}$ and Mishra et al $(0.8 \%) .{ }^{14}$ Von Willebrand disease is said to be the most common inherited bleeding abnormality. ${ }^{14,15}$

In our study, AUB-E contributed to $2 \%$ of patients and its aetiological diagnosis is limited by unavailability of tests in places.

In present study women with AUB-P, were managed with hysteroscopic polypectomy, and sent for histopathology to rule out any malignancy. In a women with Multiple polyps and fertility is not desired- LNG-IUS was inserted to avoid recurrence. Pereira et al ${ }^{16}$, stated hysteroscopic removal was the gold standard treatment for endometrial polyps. Fraser et $a{ }^{17}$ suggested that the use of LNG-IUS was useful to prevent the development of endometrial polyps.

In women with AUB-A the treatment was challenging. Hysterectomy remains the definitive treatment for women for whom fertility is not a concern. As suppressive hormonal treatments such as continuous use of oral contraceptive pills, progestogens, LNG-IUS, can temporarily induce regression of adenomyosis but prevent pregnancy. So, adenomyomectomy was offered to women who were desirous to conceive. The procedure was technically challenging as there is no clear plane between adenomyoma and normal myometrium. However, new drugs, such as selective progesterone receptor modulators, aromatase inhibitors, and anti-platelet therapy, are under development for the treatment of Adenomyosis. ${ }^{18}$

Treatment was individualized for fibroid like tranexamic acid, NSAIDS or combined oral contraceptives (COCs), mifepristone, progesterone receptor modulators such as ulipristal acetate, $\mathrm{GnRH}$ analogues were given. For failed medical treatment and eligible candidates surgery was performed. As reported by Taran et al preoperative $\mathrm{GnRH}$ analogues and ulipristal acetate treatment for 3-4 months was given to improve anemia, to reduce intraoperative blood loss and need for blood transfusion. ${ }^{19}$ NICE guideline recommends, in the absence of pressure symptoms, medical treatment may be more appropriate, particularly when fertility preservation is required. Tranexamic acid and NSAID remain the only fully noncontraceptive medical options. ${ }^{20}$

The women with simple endometrial hyperplasia without atypia with low risk for progression to endometrial cancer were managed with progesterone therapy (Medroxy progesterone 10mg daily for 3-6 months). ${ }^{21}$ In our study Tranexamic acid and NSAID were considered the first-line therapy non- 
structural causes of AUB. In women desiring effective contraception, LNG-IUS and COCs were recommended. Cyclic oral progestins (from day 5 to 25), are recommended if COCs are contraindicated; similar approach of management was recommended by Khrouf et al. ${ }^{22}$ NSAIDs are to be avoided in patients with bleeding disorders or platelet function abnormalities. $^{23}$

\section{CONCLUSIONS}

FIGO - PALM COEIN structured diagnostic classification of abnormal uterine bleeding and their respective management options have been applied.

\section{REFERENCES}

1. ACOG committee opinion number 557. Management of acute abnormal uterine bleeding in a nonpregnant reproductive aged woman. ACOG. April 2013.

2. Munro MG, Critchley HOD, Fraser IS. The two FIGO systemsfor normal and abnormal uterine bleeding symptoms and classification of causes of abnormal uterine bleeding in the reproductive years: 2018 revisions. Int J Gynecol Obstet. 2018;143:393-408.

3. Jetley S, Rana S, Jairajpuri ZS. Morphological spectrum of endometrial pathology in middle-aged women with atypical uterine bleeding: A study of 219 cases. J Midlife Health. 2013;4(4):216-20.

4. Pillai SS. Sonographic and histopathological correlation and evaluation of endometrium in perimenopausal women with abnormal uterine bleeding. Int $\mathrm{J}$ Reprod Contracep Obstet Gynaecol. 2014;3:113-7.

5. Betha K, Malavatu L, Talasani S. Distribution of causes of abnormal uterine bleeding using new FIGO classification system-PALM COEIN: a rural tertiary hospital based study. Int J Reprod Contracep Obstet Gynaecol. 2017;6(8):3523-7. www.ijrcog.org. pISSN 2320-1770 | eISSN 2320-1789.

6. Mishra D, Sultan S. FIGO's PALM-COEIN Classification of Abnormal Uterine Bleeding: A Clinicohistopathological Correlation in Indian Setting. J Obstet Gynaecl India. 2017;67(2):119-125. doi: 10.1007/ s13224-016-0925-8

7. Doraiswami S, Johnson T, Rao S, Rajkumar A, Vijayaraghavan J, Panicker VK. Study of endometrial pathology in abnormal uterine bleeding. J Obstet Gynaecl India. 2011;61(4):426-30.

8. Qureshi FU, Yusuf AW. Distribution of causes of abnormal uterine bleeding using the new FIGO classification system. J Pak Med Assoc. 2013;63(973).

9. Taran FA, Weaver AL, Coddington CC, Stewart EA. Characteristics indicating adenomyosis coexisting with leiomyomas: a case control study. Hum Reprod.
2010;25(5):1177-82.

10. Templeman C, Marshall SF, Ursin G, Horn-Ross PL, Clarke CA, Allen M, et al. Adenomyosis and endometriosis in the California Teachers Study: Reproductive and lifestyle correlates. Fertil Steril. 2008;90(2):415-24.

11. Weiss G, Maseelall P, Schott LL, Brockwell SE, Schocken M, Johnston JM. Adenomyosis a variant, not a disease? Evidence from hysterectomized menopausal women in the Study of Women's Health Across the Nation (SWAN). Fertil Steril. 2009;91 (1):201-6.

12. Singh K, Agarwal C, Pujani M, Raychaudhari S, Sharma N, Chauhan V, et al. A Clinicopathological Correlation of International Federation of Gynecology and Obstetrics's PALM-COEIN Classification of Abnormal Uterine Bleeding: Indian Scenario. J Midlife Health. 2019;10(3):147-52.

13. Khare A, Bansal S, Sharma P, Elhence N, Makkar N, Tyagi Y. Morphological spectrum of endometrium in patients presenting with dysfunctional uterine bleeding. Peoples J Sci Res. 2012;5:13-6.

14. Edlund M, Blomback M, von Schoultz B, Andersson $\mathrm{O}$. On the value of menorrhagia as a predictor for coagulation disorders. Am J Hemat.1996;53:234-8.

15. Kadir RA, Economides DL, Sabin CA, Owens D, Lee CA. Frequency of inherited bleeding disorders in women with menorrhagia. The Lancet.1998;351:485-9.

16. Pereira N, Petrini AC, Lekovich JP, Elias RT, Spandorfer SD. Surgical management of endometrial polyps in infertile women: a comprehensive review. Surg Res Pract. 2015;2015:914390.

17. Fraser IS. The promise and reality of the intrauterine route for hormone delivery for prevention and therapy of gynecological disease. Contraception. 2007;75 (6 Suppl): S112-S117.

18. Vannuccini S, Luisi S, Tosti C, Sorbi F, Petralgia F. Role of medical therapy in the management of uterine adenomyosis. Fertil Steril. 2018;109(3):398405. 10.1016/j.fertnstert.2018.01.013

19. Khrouf M, Terras K. Diagnosis and Management of Formerly Called "Dysfunctional Uterine Bleeding" According to PALM-COEIN FIGO Classification and the New Guidelines. J Obstet Gynaecl India. 2014;64(6):388-93.

20. NICE Clinical Guideline 44. Heavy menstrual bleeding: Asssessment and management. National Institute for Health and Clinical Excellence (NICE); 2018 March.

21.Ferenczy A, Gelfand M. The biologic significance of cytologic atypia in progestogen-treated endometrial hyperplasia. Am J Obstet Gynecol. 1989;160 (1):126-31.

22. Badiani B, Chiumente M, Messori A. Ulipristal acetate for pre-operative management of uterine fibroids was effective Modeling outcomes and costs. J Obstet Gynaecl India. 2014;64:388-93.

23. Kadir RA, Lukes AS, Kouides PA, Fernandez H, Goudemand J. Management of excessive menstrual bleeding in women with hemostatic disorders. Fertil Steril. 2005;84:1352-9. 